\title{
Colonic carcinoma in two adult cystic fibrosis patients
}

\author{
H CHAUN BM FRCP FRCPC, B PATY BSc MD, EM NAKIELNA MB MRCP(UK) FRCPC, N SCHMIDT MD FRCSC, \\ JK HOLDEN MD FRCPC, B MELOSKY MD FRCPC
}

\begin{abstract}
H Chaun, B Paty, EM NaKielna, N Schmidt, JK Holden, B Melosky. Colonic carcinoma in two adult cystic fibrosis patients. Can J Gastroenterol 1996;10(7):440-442. Two adult women with cystic fibrosis (CF) who developed colonic carcinoma, both at age 31 , are described. In both patients the carcinoma occurred in the midtransverse colon. The diagnosis had not been suspected, partly because of the patients' relatively young age. In case 1, the symptoms also mimicked the distal intestinal obstruction syndrome. At diagnosis she was shown to have metastases to the regional lymph nodes. In case 2, despite a long history of chronic pulmonary and sinus disorders, CF was not diagnosed until the patient was 36 years old. The incidence of gastrointestinal malignancies has been shown to be significantly increased in patients with CF. As the life expectancy of the CF population increases, vigilance for gastrointestinal cancers in CF patients is important, as illustrated by these two cases.
\end{abstract}

Key Words: Adults, Carcinoma, Cystic fibrosis, Colon

\section{Cancer du côlon chez deux adultes atteintes de mucoviscidose}

RÉSUMÉ : On décrit ici le cas de deux patientes atteintes de mucoviscidose et ayant toutes deux développé un cancer du côlon à l'âge de 31 ans. Chez les deux patientes, le cancer s'est attaqué à l'hémicôlon transverse. Le diagnostic n'avait pas été soupçonné, en partie à cause du jeune âge relatif des patientes. Dans le premier cas, les symptômes ressemblaient à ceux du syndrome d'obstruction intestinale distale. Au moment du diagnostic, elle avait des métastases aux ganglions lymphatiques régionaux. Dans le deuxième cas, malgré de longs antécédents de maladie chronique des poumons et des sinus, la muscoviscidose n'a été diagnostiquée que lorsque la patiente a atteint 36 ans. La fréquence des néoplasies gastrointestinales s'est révélée significativement plus grande chez les patients atteints de mucoviscidose. À mesure que l'espérance de vie ces patients augmente, il faudra faire preuve d'une plus grande vigilance pour dépister chez eux les cancers du tractus digestif, comme l'illustrent ces deux cas.
A lthough the overall incidence of malignant disease in patients with cystic fibrosis $(\mathrm{CF})$ is within the expected range, their risk of gastrointestinal cancers is significantly increased $(1,2)$. The excess risk of gastrointestinal cancers in CF patients is confined to adults. As reported by Neglia et al (1), nine of 24 gastrointestinal cancers worldwide were located in the large intestine. Details of these patients were not presented.

Two adult CF patients, diagnosed and treated for colonic carcinoma, are reported. One patient had metastases to the regional lymph nodes.

\section{CASE PRESENTATIONS}

Case 1: A 31-year-old woman was admitted to hospital because of acute respiratory infection and a one-year history of abdominal pain. CF was diagnosed at age 3 . Her genotype was later identified as Delta-F 508/Delta-F 508. She had no family history of CF or colon cancer. She had 'bulky stools' when growing up but was not treated with pancreatic enzymes, and had no major respiratory problems until age 18 . Her pain was colicky, located across the upper abdomen and down the right side, accompanied by visible lumps, constipation, occasional vomiting, poor appetite and weight loss. She had a mild

The first case was presented as a poster at the 20th European Cystic Fibrosis Conference held June 18 to 21, 1995 in Brussels, Belgium

Adult Cystic Fibrosis Clinic and Departments of Medicine, Surgery and Pathology, St Paul's Hospital, and University of British Columbia,

Vancouver, British Columbia

Correspondence and reprints: Dr H Chaun, Suite 601 - 805 West Broadway, Vancouver, British Columbia V5Z 1K1. Telephone

604-872-0717, fax604-872-7921, e-mail 74172.1602@compuserve.com

Received for publication November 24, 1995. Accepted April 2, 1996 


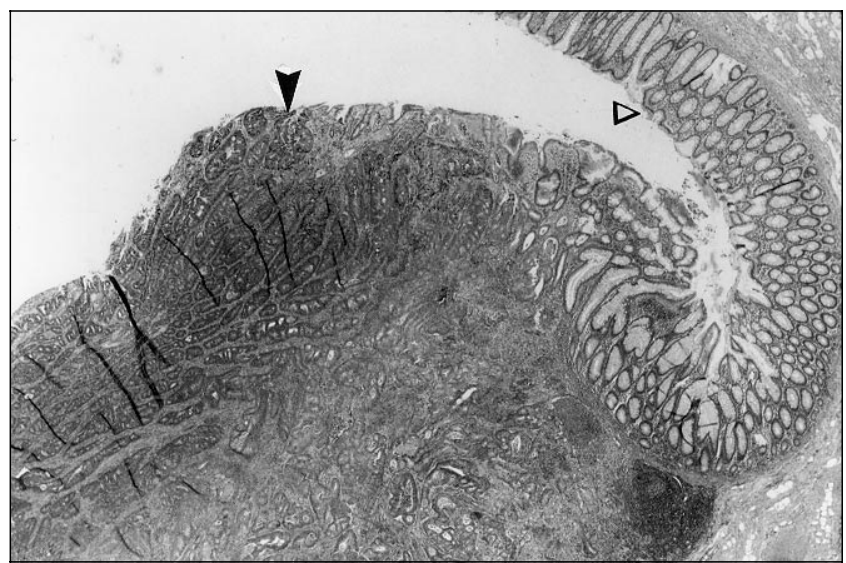

Figure 1) Photomicrograph of transverse colon demonstrating moderately differentiated infiltrating adenocarcinoma (solid arrow) and adjacent non-neoplastic colonic mucosa (open arrow) (hematoxylin and eosin x13.4)

microcytic anemia. She was admitted to a local hospital once a month for the preceding four months and received treatment for the distal intestinal obstruction syndrome (DIOS). Colonoscopy and biopsies showed an obstructive carcinoma in the midtransverse colon. A single contrast hypaque enema revealed a $6 \mathrm{~cm}$ circumferential narrowing of the transverse colon. A computerized tomographic scan showed thickening of the transverse colon and possible local lymphadenopathy. The carcinoma was surgically resected.

Pathology: Within the centre of the resected segment of colon there was an annular $4 \times 6 \mathrm{~cm}$ tumour mass with heaped-up margins and central ulceration, causing a focal stricture of the colonic lumen. On cut section the tumour measured $2 \mathrm{~cm}$ in maximum thickness. Microscopic sections showed a moderately differentiated adenocarcinoma (Figure 1) that infiltrated the full thickness of the bowel wall into the subserosal fat. Eight of 13 regional lymph nodes were positive for metastatic adenocarcinoma (Figure 2). Involvement varied from subcapsular microscopic foci to extensive replacement of the node and involvement of extranodal soft tissue.

She had adjuvant therapy with 5 -fluorouracil and levamisole. Seven months later there was no evidence of recurrent carcinoma.

Case 2: A 51-year-old woman had a long history of bronchitis, recurrent pneumonia, bronchiectasis and chronic sinusitis. At age eight a bolus of hair was surgically removed from the cecum. She had chronic abdominal pain and constipation attributed to 'nerves', which was treated with laxatives. Testing at age 30 revealed hemoglobin of $3.1 \mathrm{mmol} / \mathrm{L}$ ) and stools positive for hemoccult. Anemia was attributed to the effects of chronic disease and hemorrhoids.

Several months later (and two months after a right upper lobectomy for bronchiectasis) she developed severe abdominal cramps. A barium enema showed a tumour mass in the transverse colon. At age 31, a carcinoma in the transverse colon was resected. Her paternal grandfather had colonic cancer.

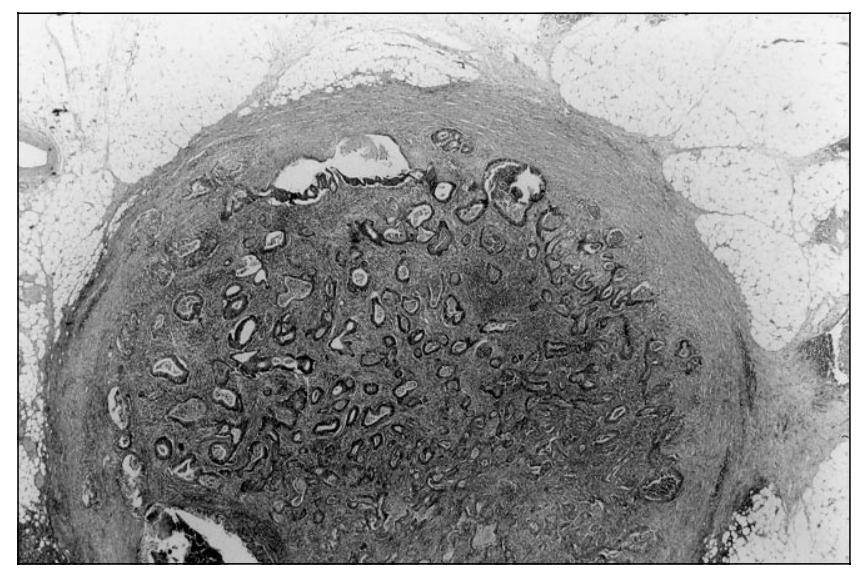

Figure 2) Photomicrograph of pericolic lymph node showing extensive replacement by metastatic colonic adenocarcinoma (hematoxylin and eosin $\times 13.4$ )

Despite the long history of chronic pulmonary and sinus disorders, CF was not diagnosed until she was 36 years old. Her genotype was later identified as Delta-F 508/unknown. Two of her five brothers were also shown to have CF. She has never required pancreatic enzyme supplements.

Pathology: Within the resected segment of the transverse colon there was a fungating markedly constrictive tumour mass measuring about $7 \mathrm{~cm}$ in diameter. Microscopic sections showed a relatively well differentiated adenocarcinoma extending into the bowel wall but not infiltrating through it. Sections through seven lymph nodes showed no evidence of metastatic tumour.

In the 20 years since her colonic resection she has had intermittent diarrhea and constipation, with occasional cramps across the lower abdomen. She had three small colonic adenomas demonstrated at colonoscopy in the past two years.

\section{DISCUSSION}

The two patients described here were among 187 patients seen in the British Columbia Adult CF Clinic in Vancouver from 1980 to 1995 . Both patients were 31 years old when the carcinoma was diagnosed. In this age group, carcinoma of the colon is distinctly rare. In British Columbia, the incidence of colonic carcinoma in females from birth to age 34 was 0.5/100,000 in 1992 (3).

Abdominal pain, including the DIOS $(4,5)$, and iron deficiency (6) are common in patients with CF. The diagnosis of colonic carcinoma in both patients was delayed. In case 1 , her symptoms mimicked those of the DIOS, although her abdominal pain was of relatively recent onset. At diagnosis she had metastatic involvement of the regional lymph nodes. In case 2, her severe anemia had been wrongly diagnosed. Despite a long history of chronic pulmonary and sinus disorders, CF was not diagnosed until five years after the carcinoma was resected. Incidentally, the carcinoma was located in the midtransverse colon in both patients.

In the North American and European cohort studies (1), 


\section{TABLE 1 \\ Literature data: Increased gastrointestinal cancer risk in patients with cystic fibrosis (CF)}

Cancer Data from 115 American and 33 Canadian CF centres from 1985 to 1992 : 28,511 patients (164,764 person-years of follow-up)

37 histologically confirmed cancers: 13 gastrointestinal (GI) (one esophagus, one stomach, two small intestine, three large intestine, five liver or biliary tract, one pancreas)

\begin{tabular}{lccc}
\hline Site & Observed & Expected & Observed:expected \\
\hline All & 37 & 45.6 & 0.8 \\
GI & 13 & 2 & 6.5 \\
& & \\
Cancer data from 377 CF centres or physicians in 17 European \\
countries from 1982 to $1994: 24,500$ patients \\
41 cancers (39 histologically confirmed): 11 Gl (one esophagus, \\
one small intestine, six large intestine, two pancreas, one \\
retroperitoneum) \\
\hline Site & Observed & Expected & Observed:expected \\
\hline GI & 11 & 1.7 & 6.4 \\
\hline
\end{tabular}

genotype information was available for $21 \mathrm{CF}$ patients with cancers (15 Europeans and six North Americans). Fourteen patients $(67 \%)$ were homozygous for the Delta-F 508 mutation. One of our patients was homozygous for Delta-F 508 and the other was shown to have Delta-F 508/unknown mutation. Delta-F 508 is the most common mutation of CF chromosomes, occurring in approximately $78 \%$ of North American Caucasians with CF (7). In British Columbia, the Delta-F 508 mutation was found in $76 \%$ of 162 CF chromosomes on DNA analysis (8). A large number of other mutations are represented in the remaining $\mathrm{CF}$ chromosomes.

Recently, specific genes have been identified for hereditary nonpolyposis colorectal cancer (9). Detailed genotypic analysis can determine whether specific genotypes are responsible for colon cancer in CF patients. These patients should also be examined for all the genes known to be

\section{REFERENCES}

1. Neglia JP, FitzSimmons SC, Maisonneuve P, et al. The risk of cancer among patients with cystic fibrosis. N Engl J Med 1995;332:494-9.

2. Sheldon CD, Hodson ME, Carpenter LM, et al. A cohort study of cystic fibrosis and malignancy. Br J Cancer 1993;68:1025-8.

3. British Columbia Cancer Agency Annual Report 1993-1994. Vancouver: British Columbia Cancer Agency, 1995:33.

4. Chaun H, Nakielna EM, Burdge DR, et al. Gastroenterological disorders in adults with cystic fibrosis. XIth International Cystic Fibrosis Congress. Dublin, 1992. (Abst MP78)

5. Weller P, Williams J. Clinical features, pathogenesis and management of meconium ileus equivalent. J R Soc Med 1986;79(Suppl):36-7.

6. Pond MN, Conway SP. Iron deficiency in young adult CF patients. Pediatr Pulmonol 1993;(Suppl 9):284. (Abst 302)

7. Lemna WK, Feldman GL, Kerem B-S, et al. Mutation analysis for heterozygote detection and the prenatal diagnosis of cystic fibrosis. N Engl J Med 1990;322:291-6. associated with an increased risk of colorectal cancer. A possible relationship between these known genetic abnormalities and the CF gene needs to be explored.

There is well documented evidence that the risk of gastrointestinal cancers is significantly increased in CF patients (Table 1 ). For CF patients 20 to 29 years old, the odds ratio for all gastrointestinal cancers is 20.1 (1). Nine of 24 gastrointestinal cancers reported worldwide occurred in the large intestine (1) (details of these patients were not provided).

Several possible explanations for the excess risk of gastrointestinal cancers in CF patients have been proposed. The heightened risk may be related to the differential localization and expression of the CF transmembrane conductance regulator gene in various organs and the varying sensitivities of individual organs (1). Another possible explanation is the effect of the CF disease process on the digestive system. Chronic pathological changes in organs of the digestive system, leading to increased cell turnover, may predispose CF patients to excess cancer risk in the gastrointestinal tract (1). It is of interest, however, that despite the frequency of severe pulmonary disease in CF, bronchogenic carcinoma has never been reported in association with CF. Steatorrhea, which is common in patients with $\mathrm{CF}$, has been linked to small bowel malignancy in patients with celiac disease (10). Barrett's esophagus, a known premalignant disorder, has been reported in CF patients (11). CF patients with malabsorption have been shown to be deficient in the anti-oxidants selenium and vitamin $\mathrm{E}$, which may be protective against cancer $(12,13)$.

\section{CONCLUSIONS}

As the life expectancy of the CF population increases, and with well documented evidence that adult CF patients are at an increased risk of developing gastrointestinal malignancies, heightened awareness of gastrointestinal cancers is clearly important in the continued management of adult CF patients with unexplained persistent gastrointestinal symptoms.

8. Langlois S. Characterization of the cystic fibrosis gene and its relevance to clinical care. BC Med J 1993;35:484-6.

9. Lynch HT, Smyrk TC, Watson P, et al. Genetics, natural history, tumour spectrum, and pathology of hereditary nonpolyposis colorectal cancer: an updated review. Gastroenterology 1993;104:1535-49.

10. Swinson CM, Slavin G, Coles EC, et al. Coeliac disease and malignancy. Lancet 1983;i:111-5.

11. Hassall E, Israel DM, Davidson AGF, et al. Barrett's esophagus in children with cystic fibrosis: not a coincidental association. Am J Gastroenterol 1993;88:1934-8.

12. Stead RJ, Redington AN, Hinks LJ, et al. Selenium deficiency and possible increased risk of carcinoma in adults with cystic fibrosis. Lancet 1985;ii:862-3.

13. Bostick RM, Potter JD, McKenzie DR, et al. Reduced risk of colon cancer with high intake of vitamin E: the Iowa Women's Health Study. Cancer Res 1993;53:4230-7. 


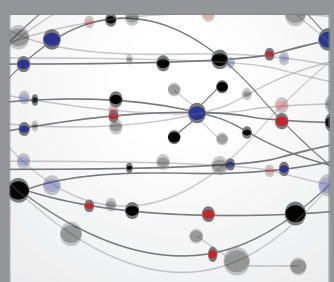

The Scientific World Journal
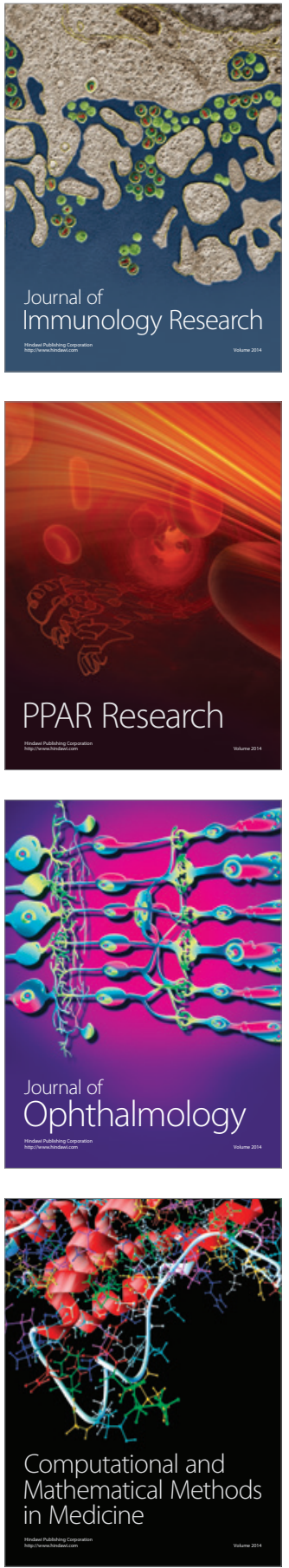

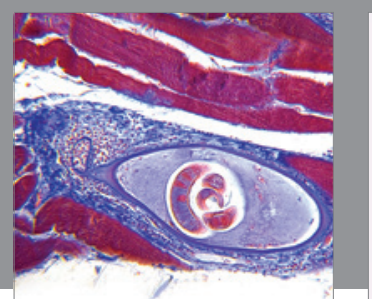

Gastroenterology Research and Practice

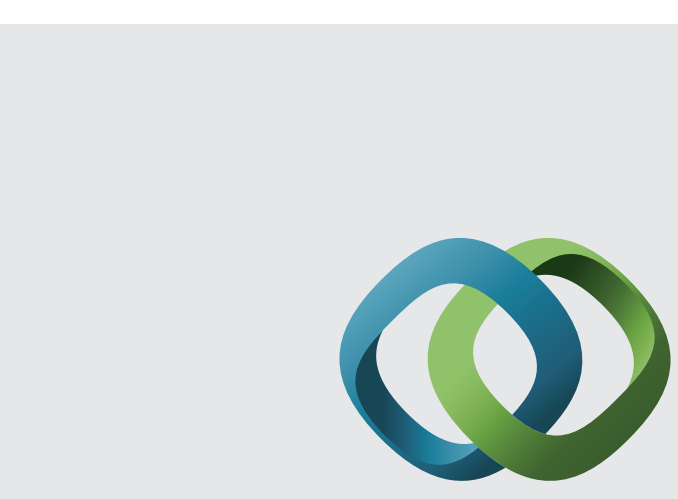

\section{Hindawi}

Submit your manuscripts at

http://www.hindawi.com
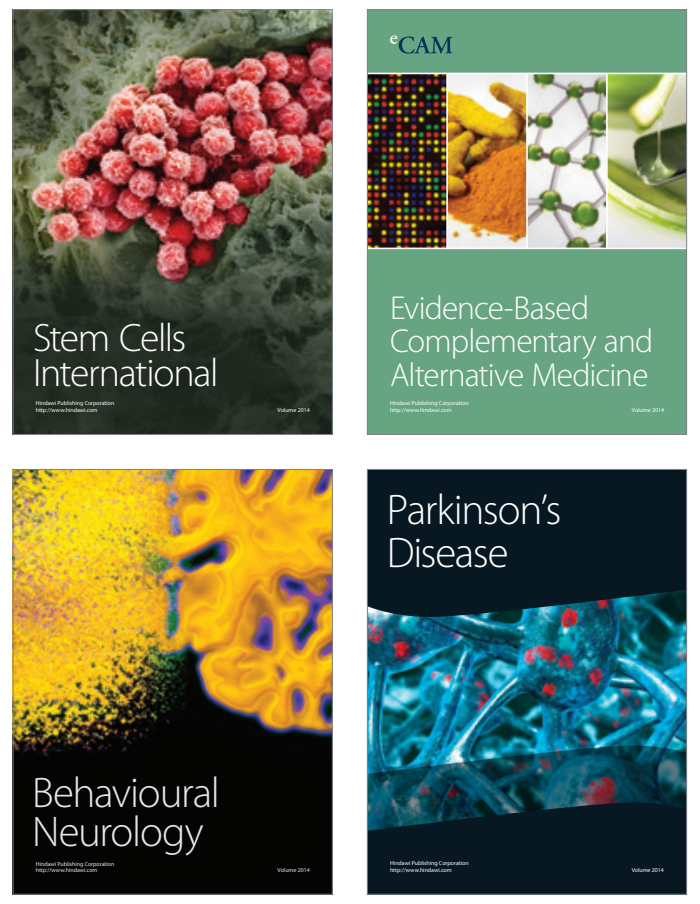
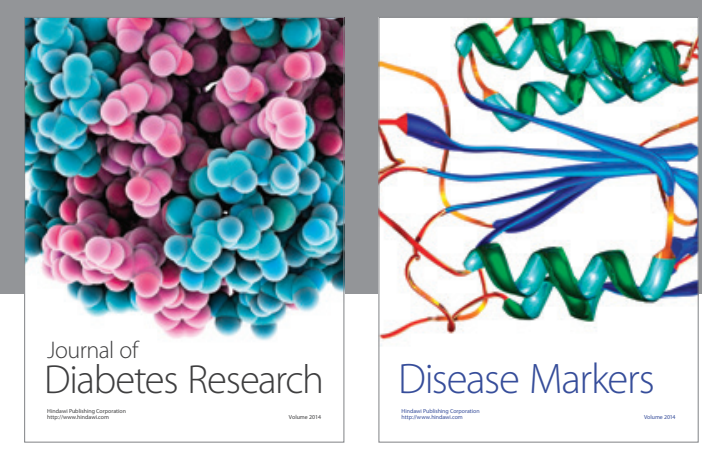

Disease Markers
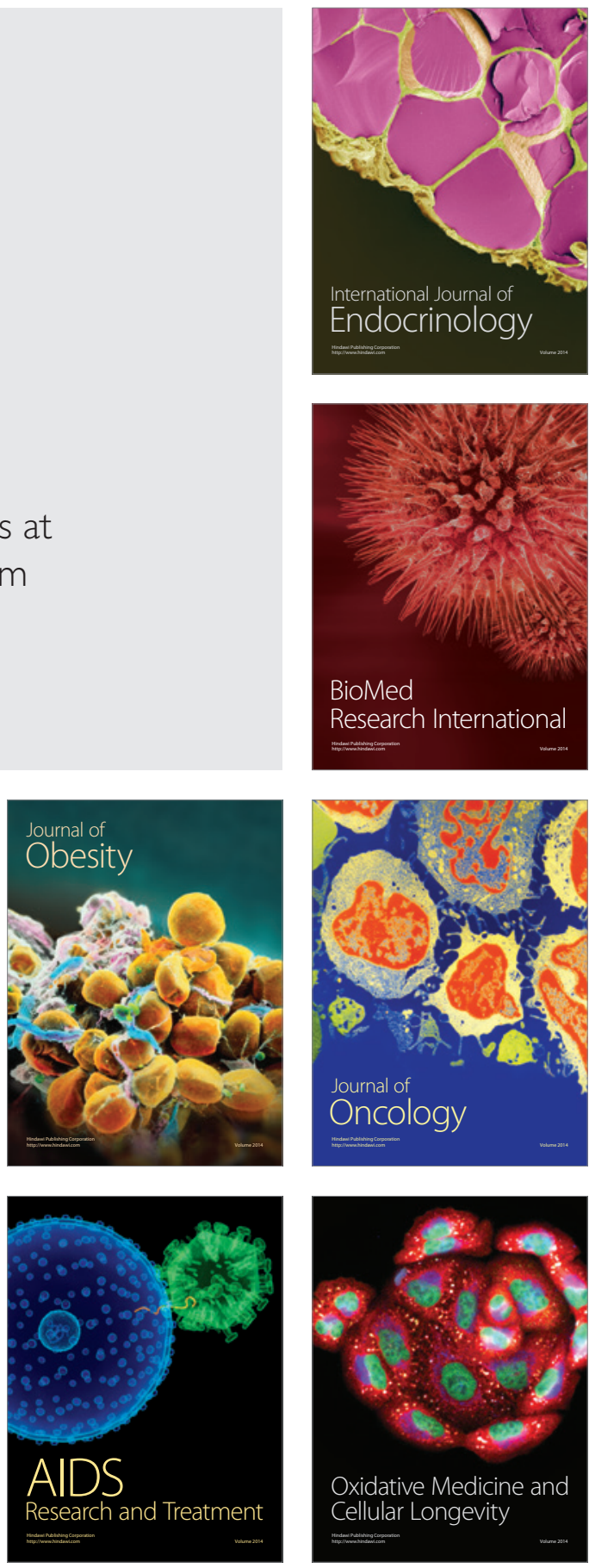